\title{
PRODUTIVIDADE PRIMÁRIA, BIOMASSA E FATORES LIMITANTES NA ÁREA ESTUARINA SW DA BAIA DE TODOS OS SANTOS *
}

\author{
JORGE FALCÃO PAREDES \\ VERA MARIA CARVALHO PEIXINHO \\ RONAN REBOUÇAS CAIRES DE BRITO \\ Instituto de Biologia, Universidade Federal da Bahia, Salvador, BA, Brasil
}

\section{SYNOPSIS}

The primary production by $C^{14}$, standing crop as ratio of particulate carbon/nitrogen and biossay tests concerning to dissolved nitrogen and phosphons were investigated in the SW estuarine mangrove area of the Bay of Todos os Santos (Brazil) during 10 months. The phyto. plankton displaied in this area a mean density of $9 \times 10^{5}$ cells/liter. The primary productivity showed an average range of 9.52 to 10.93 mgC/ $/ \mathrm{m}^{3} / \mathrm{h}$, representing the rate about $45 \mathrm{~g} \mathrm{C/m} /$ year or $181 \mathrm{~g} \mathrm{C} / \mathrm{m}^{2} /$ year. Phytoplankton fraction under $35 \mu$ at the stations 0 and 1 was responsible for the most $C^{14}$ uptake. A negative relationship between primary production and limiting nitrogen and phosphorus was verified. Fe. bruary samples exhibited the most drastic situation regarding to $N$ and $P$, as limiting factors; an opposite situation corresponded to June and July, The relationship between particulated carbon and nitrogen showed a concentration area among the ranges of $400 / 1400 \mathrm{mgC} / \mathrm{m} 3 /$ and $4 / 28$ $\mathrm{mg}^{\mathrm{N}} / \mathrm{m}^{3}$, The ratios $C / N$ revealed the most of times a short variation.

\section{Introduçāo}

A Baía de Todos os Santos (130 00' S e 38030' W) representa com seus $800 \mathrm{~km}^{2}$ uma bacia naturalmente relevante em termos de produção, nela desembocando cinco estuários (Fig. 1). Embora seus caudais sejam bem variáveis, deve-se salientar que pelo menos os dois estuários da região $\mathrm{SW}$ se situam em áreas de elevada precipitação (2.000-2.300 mm anuais). Estes e todos os outros estuários são marginados por extensas áreas de mangue.

Os estuários dos rios Jacuruna e Jaguaripe, sobre os quais incidiram nossos estudos, são estuários de barreira formada pela Ilha de Itaparica, a maior ilha de entre outras que emergem na Baía de Todos os Santos. Esta Ilha dá origem a um canal, cujas correntes são condicionadas pelos caudais daqueles rios e, pelas correntes de maré incidindo dum e doutro lado desta ilha e ainda em parte pelo rio Paraguassu. Os rios Jacuruna e Jaguaripe têm influência real das marés. $\mathrm{O}$ rio Jacuruna ao contrário do rio Jaguaripe tem um percurso relativamente curto e de fundo raso. $\mathrm{Na}$ região Sul do Canal de Itaparica em frente a Jiribatuba, a amplitude das marés é em valores médios anuais, de 1,0 a 2,5 metros.

Peixinho (1972) e Santos (1973) fazem um circunstanciado histórico das pesquisas que tiveram lugar na Baía de Todos os Santos e destas apenas os trabalhos de Zimmermann (1916), Peixinho (1972) e Santos (1973) se reportam ao fitoplâncton, numa forma de análise florística com exceção do segundo destes trabalhos, que visa já a pesquisa de vários parâmetros físico-químicos da área estudada que a autora relaciona com dados de produção em termos de matéria em suspensão, complementada por dados de abundância e freqüência relativa do fitoplâncton. Este trabalho diz respeito a uma uas enseadas da Bara de Todos os Santos (Baía de Aratu).

Presentemente, algumas áreas da Baía de Todos os Santos estão marginadas por algumas indústrias que poderão ou já estão criando alguns problemas na qualidade de suas águas. A área SW onde se concentram os estudos do presente trabalho é, não só a área mais afastada daquelas, mas também aquela que prima por ausência de indústrias. No entanto, a bacia do rio Jaguaripe é enquadrada por áreas de cultivo que poderão drenar de forma conspícua, pesticidas que venham a ser utilizados indiscriminadamente devendo-se tanto mais atender a que esta é uma área de intensa precipitação.

O presente trabalho é por isso um dos primeiros estudos sobre produção primária levados a efeito na Baía de Todos os Santos que, pelo atrás referido, deve ser considerada uma área estuarina mal conhecida, apesar de toda a sua importância que "a priori" se infere deva ter. Só o seu conhecimento e uma avaliação de suas potencialidades em termos de produção, poderão oferecer argumentos à definição e preservação de áreas de pesca e aquacultura, como etapas e objetivos do Projeto Ambientes Estuarinos, integrando vários sub-projetos.

De acordo com Odum (1971), os estuários tendem a ser caracteristicamente mais produtivos do que qualquer outra área hídrica, quer marinha quer continental.

Os dados constantes neste trabalho reportam-se a quatro estações, sendo duas sitas no rio Jacuruna, uma no Canal de Itaparica e outra no estuário do rio Jaguaripe.

As estaçōes 0,1 e $2 \mathrm{~A}$ coincidem com estações de ostreicultura e bentos (Fig. 1).

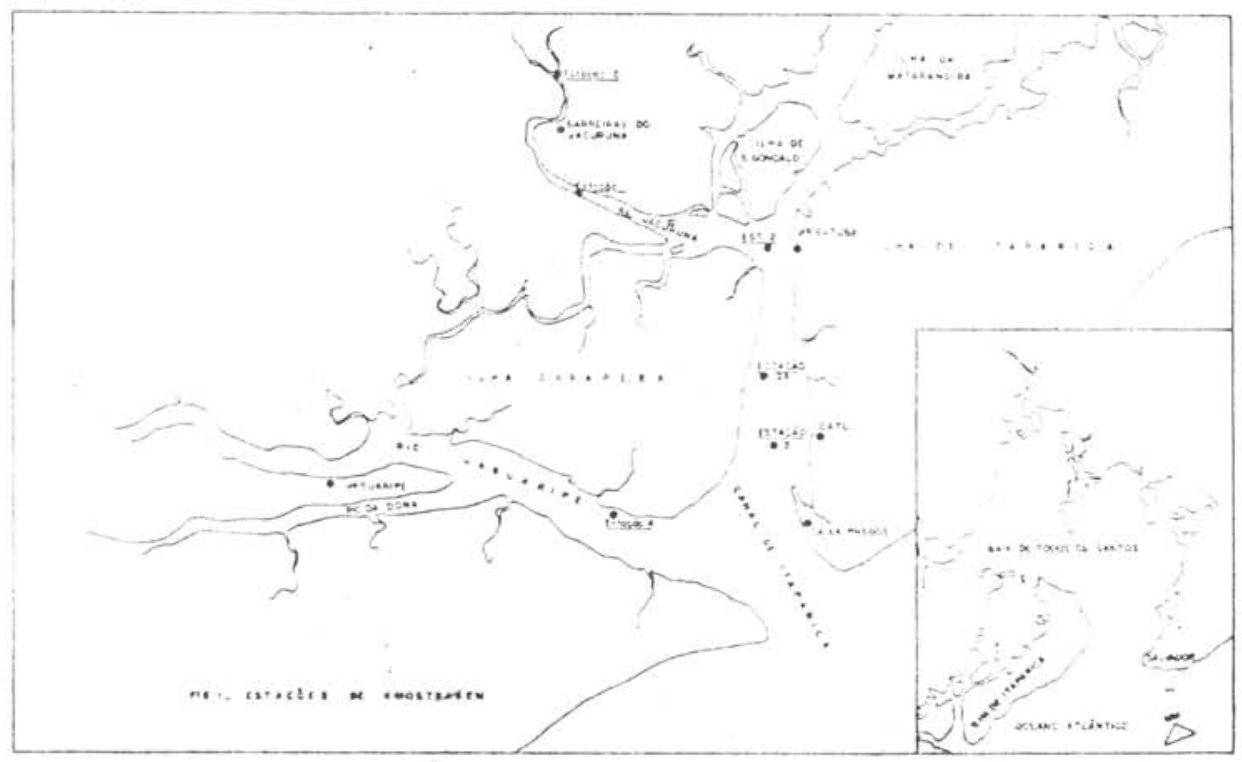

Fig. 1. Estaçōes de amostragem 
Sempre que possível manteve-se uma freqüência mensal de amostragens nestas estações repetidas uma durante o curso da enchente e outra durante o curso da vazante.

\section{Metodologia}

\section{Amostragem}

Todas as amostragens de água tomadas ao nível do disco de Secchi foram realizadas por bomba elétrica submersível e mantidas até ao laboratório em garrafas térmicas.

As incubações para avaliação da taxa fotossintética tiveram hugar imediatamente ou dentro de 2 horas.

As concentraçōes das suspensōes de seston para as análises químicas tiveram procedimento dentro de $6 / 12$ horas.

As incubações para testes biológicos só tiveram lugar dentro de 12 a 24 horas após a coleta.

\section{Alcalinidades rotal e do $\mathrm{CO}_{2}$}

Estas alcalinidades foram calculadas de acordo com o método descrito por Strickland \& Parsons (1972).

Para as determinações "in loco" do $\mathrm{pH}$ foi usado um medidor Hellige Lilliput mod. 750.

\section{Carbono Particulado (POC)}

Os substratos particulados, concentrados em membranas GF $47 \mathrm{~mm}$ de $\varnothing$ foram quantificadas pelo método de oxidação úmida descrito por Johnson (Strickland \& Parsons, 1972).

\section{Nitrogênio Particulado (PON)}

O nitrogênio particulado foi baseado na concentração das proteínas totais do seston concentrado em membranas de GF de $25 \mathrm{~mm}$ de $\varnothing$, e avaliadas pelo método de Lowry, modificado por Price (1965).

\section{A Absorção do $\mathrm{C}^{14}$}

As amostras tomadas ao nível do disco de Secchi, correspondem assim a níveis fóticos de $17 \pm 1 \%$ da sua intensidade luminosa à superfície. Amostras globais e frações coadas em redes de $35 \mu$, foram incubadas "in loco" em flutuadores que recebiam os frascos de $60 \mathrm{cc}$, após a adição de $\mathrm{Na} \mathrm{HC} \mathrm{HC}^{14} \mathrm{O}_{3}$ com uma actividade de $10 \mu \mathrm{Ci}$, representando uma eficiência de $90 \pm 5 \%$. Os períodos de incubação eram de 4 horas e de forma a cairem no período entre 09 e 16 horas. A concentração era obtida em membrana Millipore de $13 \mathrm{~mm}$ de $\varphi$ e $0,8 \mu$ de poro.

As contagens foram levadas a efeito por cintilação em fase líquida com uma eficiência de contagem de $91,25 \pm 0,25 \%$.

Contagens em duplicado mostraram um desvio padrāo de 0,5 a $1,0 \%$. Tratando-se de observações em área estuarina, o cálculo do carbono absorvido, baseou-se sempre no valor da alcalinidade do $\mathrm{CO}_{2}$.

\section{Testes de Fatores Limitantes}

Estes testes de 120 horas tiveram uma dupla função: a da avaliação das concentrações viáveis dos macro-nutrientes, nitratos e fosfatos, atuando separadamente ou conjuntamente e a da obtenção de maiores concentraçōes da população indígena inicial para uma melhor caracterização populacional, embora a abundância relativa das espécies ou gêneros presentes pudesse ser comprometida, em particular nos testes com adiçōes de nutrientes. Nestes, as diferentes taxas de desenvolvimento iriam determinar uma sucessão específica, apesar do curto espaço de tempo, decorrente das novas condições ambientais.

Cada amostra de $400 \mathrm{ml}$, mantida e trazida para o laboratório em garrafa térmica, era subdividida igualmente por 4 fras$\cos$ de cultura esterilizados. Procedia-se logo a seguir às adições de $\mathrm{N}$ e $\mathrm{P}$ nas concentrações correspondentes às condições do meio Conway. Todos os testes, inclusive o controle, levavam a adição de extrato de solo, a fim de evitar que a precipitação de sais, particularmente fosfatos, pudesse ocorrer, embora as águas estuarinas em causa, sejam obviamente, e a maior parte das vezes, dotadas de convenientes quantidades de ácidos húmicos e tânicos.

Após incubação de 120 horas em cerca de 500 luxs e $27 \pm$ $1^{\circ} \mathrm{C}$, $\gamma \mathrm{U}^{\mathrm{m}} \mathrm{m}$ de cada um aos testes eram furrados em membranas GF $20 \mathrm{~mm}$ de $\phi$ para análise imediata da clorofila a ativa pelo método de Lorenzen (1967) após extração com acetona $90 \%$.

Também de cada teste eram fixados $10 \mathrm{ml}$ com formalina neutralizada, a $1,2 \%$, servindo às análises qualitativas e quantitatıvas das populaçðes.

Os controles dos testes que em 120 horas se admite não variar muito sua composição populacional, serviram ainda para apreciação da freqüência e abundância relativa dos grupos mais representativos de algas.

As análises microscópicas incidiram sobre uma alíquota transferida para câmara de Howard, por pipeta calibrada, e após prolongada agitação. Esta câmara cuja espessura é de $0,1 \mathrm{~mm}$, possui um volume total de $30 \mathrm{~mm}^{3}$. As densidades das suspensões de fitoplâncton, permitiram, a maior parte das vezes, a utilização de subvolume de $1 \mathrm{~mm}^{3}$ baseados na utilização de retículo próprio que permitia o cálculo da conveniente área para a ampliação utilizada.

\section{Kesultados}

\section{Parâmetros Físicos e Meteorológicos}

A área sobre a qual incidiram nossas observações está incluída na área de maior precipitação pluviométrica do Recôncavo Baiano com uma média anual de 2200 a $2300 \mathrm{~mm}$, o que representa uma média mensal de 183 a $192 \mathrm{~mm}$. O grau de umidade é alto, estando sempre acima de $80 \%$. A salinidade é uma variável de pequena amplitude nas estaçōes $2 \mathrm{~A}$ e $4 \mathrm{com}$ médias em torno de 30 e $28 \%$ oo respectivamente, considerando os registros de enchente e vazante. $\mathrm{Na}$ estação 1 esta variável aumenta de amplitude com uma média de $25 \%$ oo e salinidades extremas de 3 a $31 \%$. Na estação $\mathrm{O}$ esta situação torna-se ainda mais conspícua, na medida em que mostra uma média em torno de $10 \%$; no entanto a faixa de variação vai desde 0 a $31 \%$.

$\mathrm{O}$ pH é um parâmetro sujeito a grandes variaçōes não só mensais mas ao longo do ritmo de marés.

A alcalinidade total, dos carbonatos e do $\mathrm{CO}_{2}$ são consequentemente variáveis de larga faixa impostas pelas variações do $\mathrm{pH}$ e salinidade. Assim, o $\mathrm{CO}_{2}$ em termos de peso de carbono oscilou entre 5,3 e $53,4 \mathrm{mg} \mathrm{C} / 1$ com média de $24,3 \mathrm{mgC} / 1$.

A temperatura da água é uma variável de pequena amplitude em toda a área da Baía de Todos os Santos.

\section{Parâmetros Químicos}

O "bombeamento" em larga escala de iões solúveis na água por parte da flora arbórea do ecossistema tipo mangal, impõe obviamente grandes flutuaçōes na concentração de sais necessários à produção primária.

Este processo é por sua vez compensado por um conjunto de parâmetros que vão assegurar a reciclagem relativamente rápida de toda a matéria orgânica circulante no estuário. Assim na estação 1 nas observações de janeiro a concentracão do $\mathrm{PO}_{4}-\mathrm{P}$ decaiu em cerca de 24 horas de $29,13 \mu \mathrm{g} / 1$ para 7,5 . Em contrapartida nas mesmas observaçōes o $\mathrm{NO}_{3}-\mathrm{N}$ mostrou uma pequena variacão $\mathrm{Em}$ fevereiro $\mathrm{O} \mathrm{NO}_{3}-\mathrm{N}$ subiu em cerca de 24 horas de 6,44 (enchente) para $79,41 \mu \mathrm{g} / 1$ (vazante).

A faixa de maior variação e também os valores mais elevados para $\mathrm{PO}_{4}-\mathrm{P}$ foram destacados na estação 4 apresentando o limite superior de $32,5 \mu \mathrm{g} / 1$, e um valor médio de $12,7 \mu \mathrm{g} / 1$. A que apresentou uma faixa menor nāo ultrapassando $16,0 \mu \mathrm{g} / 1$, como limite superior, foi a estação 0 com um valor médio de $8,7 \mu \mathrm{g} / 1$. As estações 1 e $2 \mathrm{~A}$ exibiram respectivamente valores médios de $9,7 \mu \mathrm{g} / 1$ e $8,2 \mu \mathrm{g} / 1$. Relativamente ao $\mathrm{NO}_{3}-\mathrm{N}$, verificaram-se, em valores médios, uma correspondência entre as estaçōes $1,2 \mathrm{~A}$ e 4 com $51,6,52,1$ e $54,0 \mu \mathrm{g} / 1$ respectivamente, e faixas de variação que por vezes ultrapassaram o limite do método $(280 \mu \mathrm{g} / 1)$. Este parâmetro na estação 0 decai para $42,9 \mu \mathrm{g} / 1$.

\section{Biomassa e Relação Carbono/Nitrogênio Particulado}

E sabido que os detritos orgânicos num estuário representam em termos de produção uma importância que pode assumir cerca de $80 \%$ da produção total. De acordo com Parsons (1975) a curva de relação $\mathrm{C} / \mathrm{N}$ assemelha-se a curva da concentração das bactérias biodegradantes de forma que um pico desta curva só posteriormente se reflete num de carbono de origem detrítica.

Infelizmente falta-nos dados do carbono orgânico dissolvido, que é sabido jogar também um importante papel na produção hídrica, admitindo-se inclusive que os seres filtradores o utilizem além do seston. A biomassa deste, dada em termos da relação carbono/nitrogênio, tem como objetivo dar uma idéia da composiçâo química do seston e observar se aqueles dois compo- 
nentes da matéria orgânica estavam sujertos a grandes variações. $\mathrm{Na}$ Figura 2 traçaram-se curvas dos valores médios das relaçōes $\mathrm{C} / \mathrm{N}$ tomados dos limites observados entre enchente e vazante. $\mathrm{Na}$ maior parte das observaçōes em qualquer das estaçōes as relações ou coincidiam ou apresentam valores muito aproximados.
A retaçāo constauaua em março na estaçāo $2 A$, que impởe um grande desvio e limites de grande amplitude, deve-se a excepcionais concentraçōes do carbono, aliás verificadas em todas as estaçōes (Peixinho et al., no prelo).

Estes valores foram secundados por baixos valores de ni-

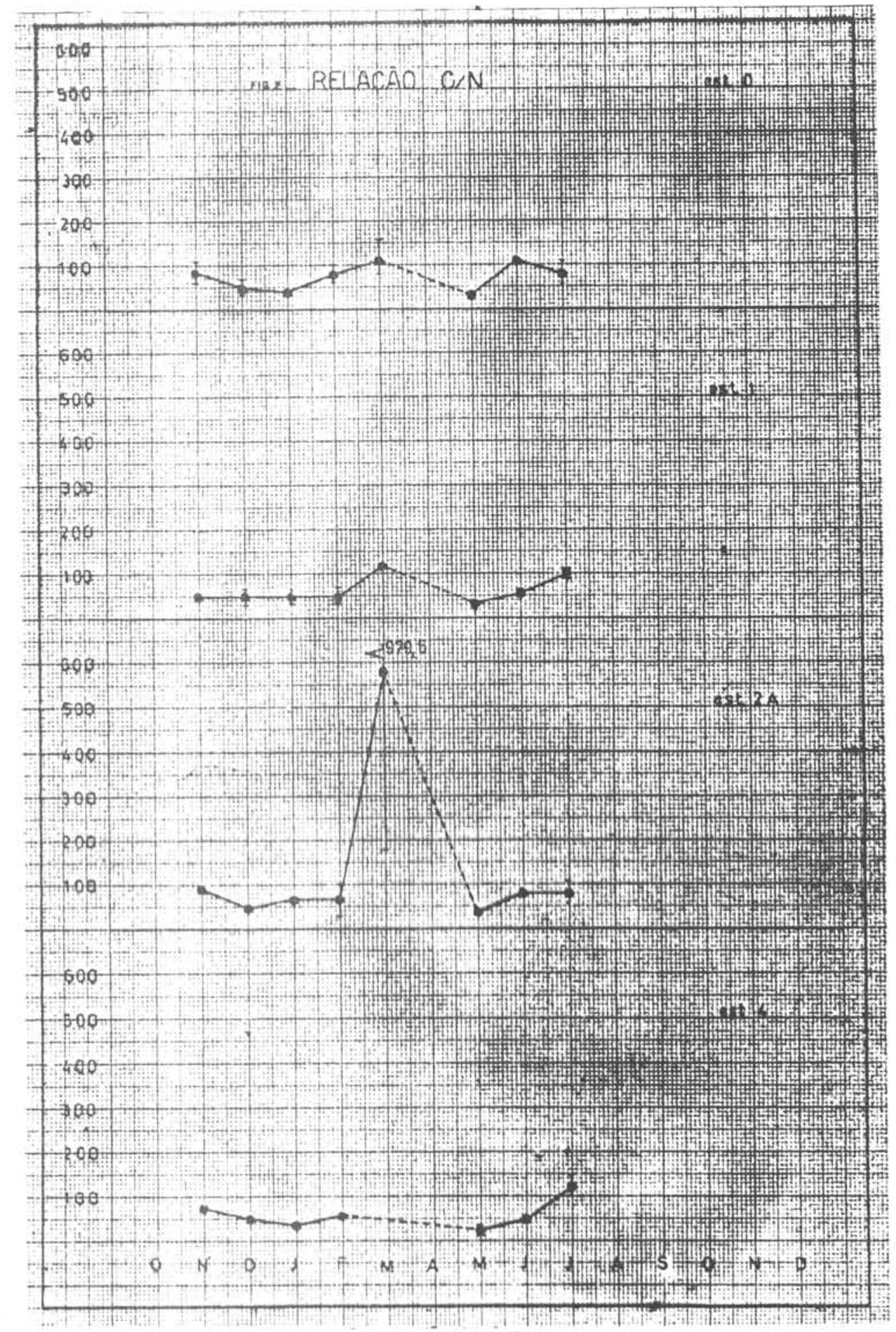

Fig. 2. Relaçấo $\bar{C} / \mathrm{N}$.

uogênio proteico, principalmente na estaçāo $\angle A$, explicando 0 discrepante resultado da relação $\mathrm{C} / \mathrm{N}$ nesta estação, que por isso mantemos sob reservas tanto mais verificando-se que a relação $\mathrm{C} / \mathrm{N}$ nesta área mantém uma faixa que varia de 50 a $70 \mathrm{com}$ valores máximos cerca de 100 e mínimos cerca de 25. Segundo vários autores (Parsons, 1975) esta relação situa-se apenas entre 10/20 em águas profundas, embora a relação para fitoplâncton vigoroso seja da ordem de 6 . Portanto a faixa de relação verificada em nossas observaçōes faz prever haver uma rápida perda de nitrogênio no seston detrítico, tal como, ocorre no mar a profundidades abaixo de zona eufótica, de acordo com este mesmo autor.

O sincronismo que parece haver entre esta relação e a con- centração de bactérias não é porém válido no concernente au carbono absorvido na fotossíntese.

\section{Taxa Fotossintética e Percentagem da Fraçăo Nanoplanctônica}

A absorção do $\mathrm{C}^{14}$ ao nível fótico do disco de Secchi foi relativamente alta na estação 0 e em parte na estação 1 nos meses de dezembro, janeiro e fevereiro com valores entre 15 e $33 \mathrm{mgC} / \mathrm{m}^{3} / \mathrm{h}$ (Fig. 3). Estes dados permitem qualificar a área destas estaçōes e durante aquele período, como de satisfatória fertilidade, chegando a ser comparáveis aos referidos por Teixeira et al., (1969) para a região estuarina de Cananéia. Porém nos meses seguintes as taxas da fotossíntese decaiem para valores abai- 


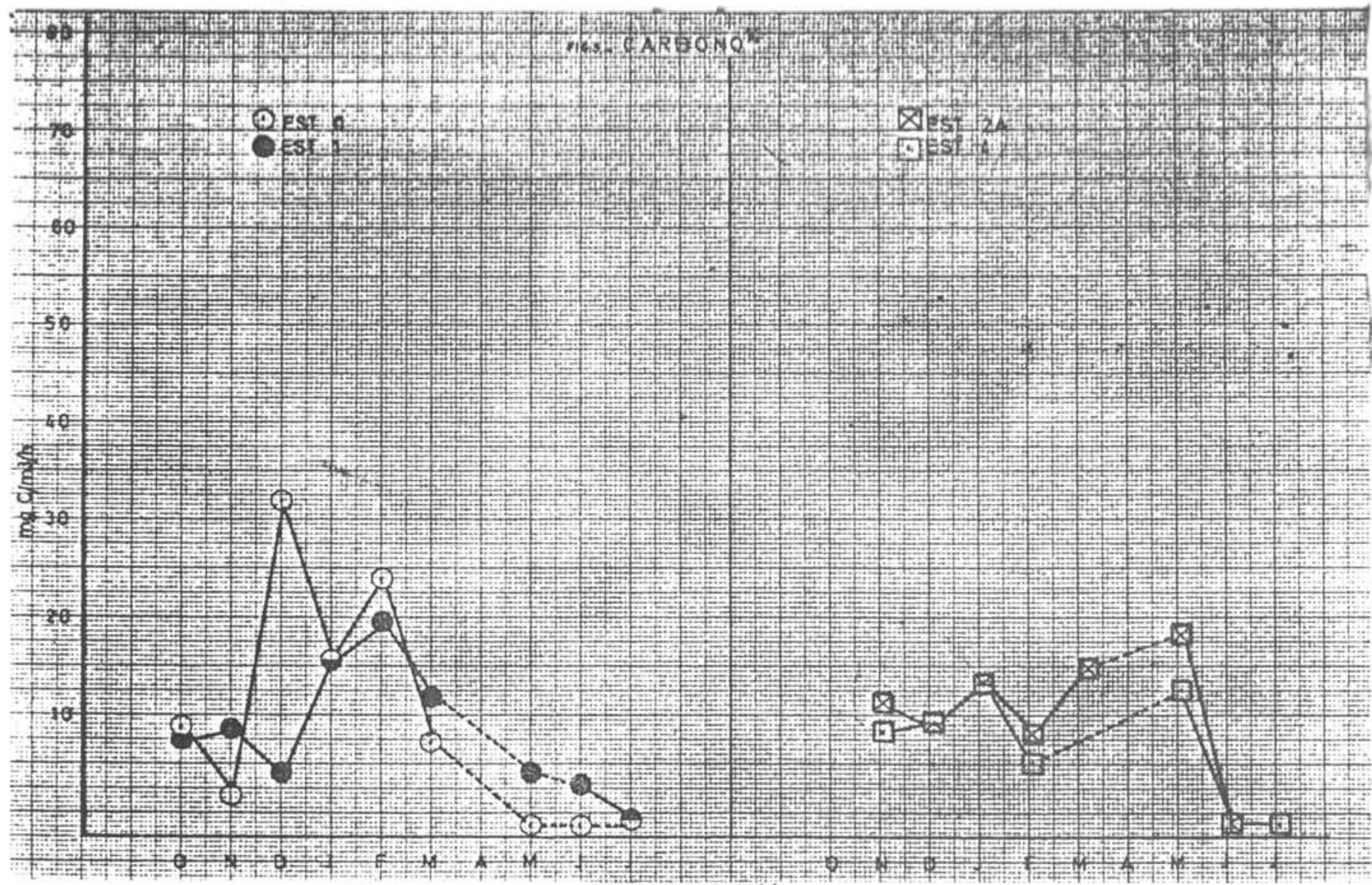

Fig. 3. Carbono ${ }^{14}$.

xo de $10 \mathrm{mgC} / \mathrm{m}^{3} / \mathrm{h}$, sendo particularmente baxos nos últimos 3 meses. As estações $2 \mathrm{~A}$ e 4 , com maior influência marinha não mostraram uma estreita correspondência com as estaçōes 0 e 1 , apresentando um pico em maio com 24 e $15 \mathrm{mgC} / \mathrm{m}^{3} / \mathrm{h}$ respectivamente. A faixa de valores verificados nas estações $2 \mathrm{~A}$ e 4 assemelham-se mais aos dados referidos por Teixeira (1972) à Baía de Ubatuba com águas de salinidades característicamente costeiras,

A quantificação das taxas fotossintéticas da fração $<35 \mu$, limite adotado para desienacão da fracão nanoplâncton revelou na maioria dos casos, assumir de 50 a $100 \%$ da população total nas estaçð̃es 0 e 1 (Fig. 4). Dois casos nesta estação e um outro na estação $2 \mathrm{~A}$, assumiram valores que ultrapassaram os $100 \%$, isto é, a fração nanoplâncton representava valores mais elevados do que a fração total. Isto se acredita deve-se a anomalias de diferentes possíveis natureza. A fração $<35 \mu$ nas estações $2 \mathrm{~A}$ e 4 apenas representam percentagens a baixo de $50 \%$ relativamente a população total.

\section{Fatores Limitantes}

As respostas às adições de nutrientes objetivadas pela variaçã̃o na concentração de clorofila $a$ ativa acham-se reproduzidas na Figura 5. Estes valores representam as concentraçōes da clorofila $(\mu \mathrm{g} / 1)$ subtraídas das concentraçōes dos respectivos controles. Em alguns casos o tempo de incubação (120 horas) foi suficiente para os testes ultrapassarem a fase de atrazo, noutros, porém, não o foi.

A utilização das populaçōes indígenas nestes testes impōem outras variáveis além das adiçôes de $\mathrm{N}$ e P: a concentração inicial da população, o vigor e as características das espécies que as compõem. Estas condiçð̋es determinam naturalmente variações que impossibilitam uma avaliação quantitativa das respostas. Assim, estes dados permitem-nos somente uma avaliação de quais elementos exerceram uma função limitante. Uma extensão, de modo grosseiro, dessa limitação, pode ser dada pelos dados de clorofila a concernentes às adições conjuntas de $\mathrm{N} e \mathrm{P}$.

Se as concentrações de clorofila $a$ variavam muito pouco relativamente ao controle, infere-se que os dois elementos adicionados separadamente ou conjuntamente, não eram necessariamente limitantes, se, pelo contrário, as concentrações exibem variaçōes conspícuas no sentido positivo isto deve corresponder a que só o elemento adicionado era necessariamente limitante. Mas se uma tal variação se processa no sentido negativo dever-se-á admitir não ser o elemento adicionado o limitante, mas sim
- outro. A adição daquele irá agravar uma situação de relação entre os dois elementos, já existentes.

Em alguns casos o nitrogênio e o fósforo se apresentam limitantes outras vezes era um só destes elementos. Os dados reproduzidos na Figura 5 mostram ter sido o nitrogénio o fator que se apresentou limitante o maior número de vezes, não só na estação 0 mas também na estação 4 . Em contrapartida, foi o fósforo que parece ter jogado este papel nas estaçסes 1 e $2 \mathrm{~A}$.

Estes dados parecem mostrar, com certa evidência, ser terrígena uma parte do fósforo que entra neste ocossistema.

A situação mais drástica, parece ter ocorrido no mês de fevereiro em todas as estações e parcialmente nos meses de outubro e março, mais ou menos reproduzida em todas as estaçōes.

$\mathrm{A}$ estação $2 \mathrm{~A}$ parece ter sido a que enfrentou as situaçōes mais críticas daqueles elementos atuando conjuntamente.

Deve-se ter contudo em consideração as circunstâncias, impostas pelas condições de trabalho, no que respeita ao tempo de armazenagem de cada amostra até o início dos testes, o qual variou de amostra para amostra.

\section{Freqüência e Abundância dos Grupos de Fitoplâncton mais Representativos}

Uma sistematização percentual dos três grandes grupos de microorganismos autotróficos, mostra que as diatomáceas, predominavam sobre os outros dois grupos. Raramente houve um equilíbrio entre eles. Algumas poucas vezes houve uma alternância daquele grupo com o grupo dos fitoflagelados (clorofíceas, criptofíceas, prasinofíceas e dimofíceas). (Tab. I)

$\mathrm{Na}$ estação $0 \mu$-diatomaceas dominaram a maior parte das vezes com exceção de novembro, fevereiro e junho. $\mathrm{Na}$ estação $2 \mathrm{~A}$ a alternância entre os grapos diatomáceas e fitoflagelados é mais notória.

Os poucos casos de dominância ou de presenças significativas do 3 ? grupo, que engloba todos os outros espécimenes foram impostos quase sempre pela presença de uma bactéria autotrófica da família das Vitreoscillacea (ordem das Beggiatoales) que chega a ser abundante em algumas populações desta área estuarina. Esta bactéria, similar ao gênero oscilatória das cianofíceas e móvel como ela, foi pelas grandes dimensōes incluida em nossas observações embora ela pertença, como aliás muitas das espécies das diatomáceas presentes, ao perifiton.

A Tabela II reproduz a frequêencia das espécies mais representativas destas análises. De cada espécie ou grupo dá-se uma idéia da abundância relativa de cada uma delas. 


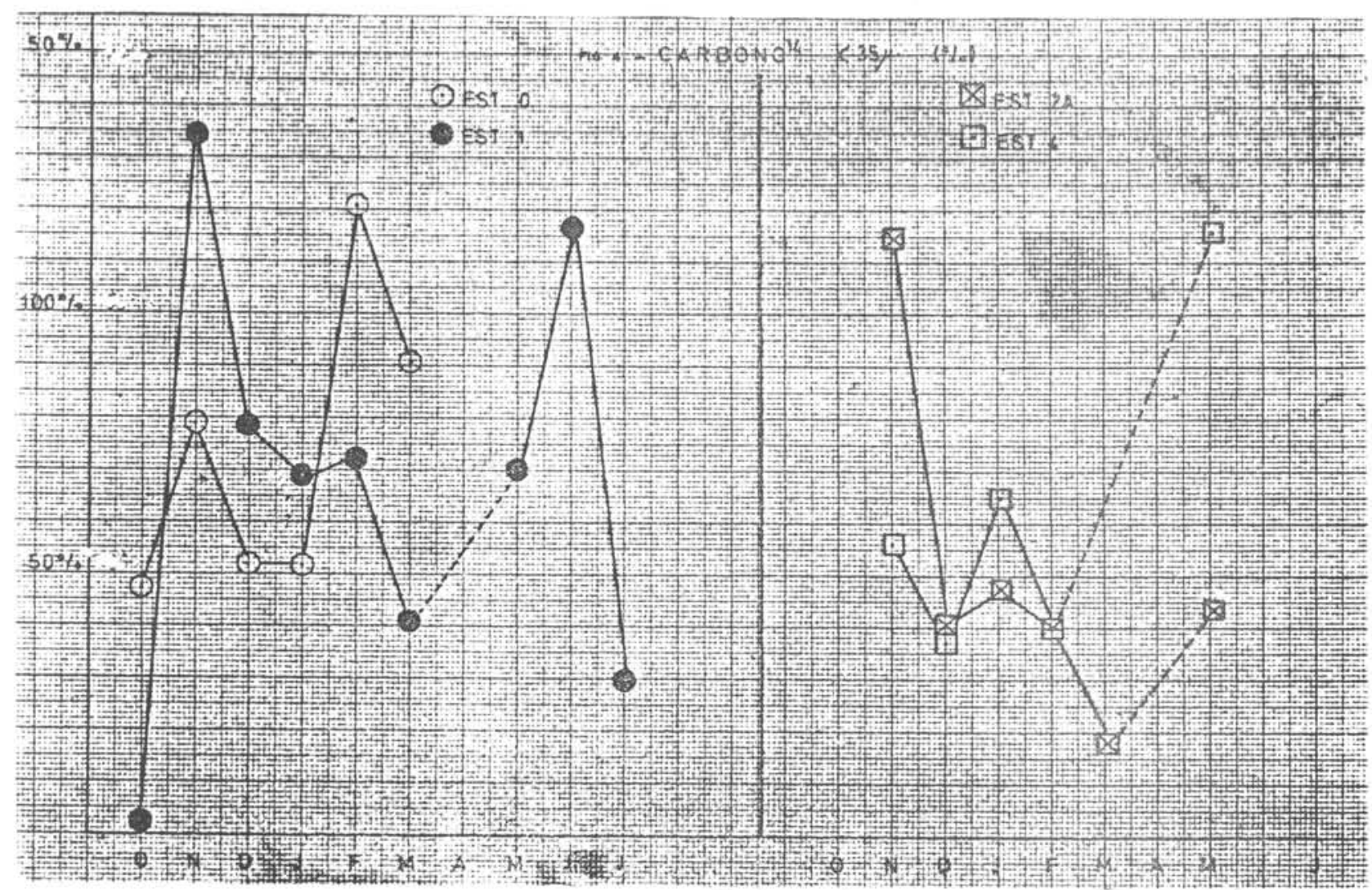

Fig. 4. Carbono ${ }^{14}<35 \mu$ (\%).

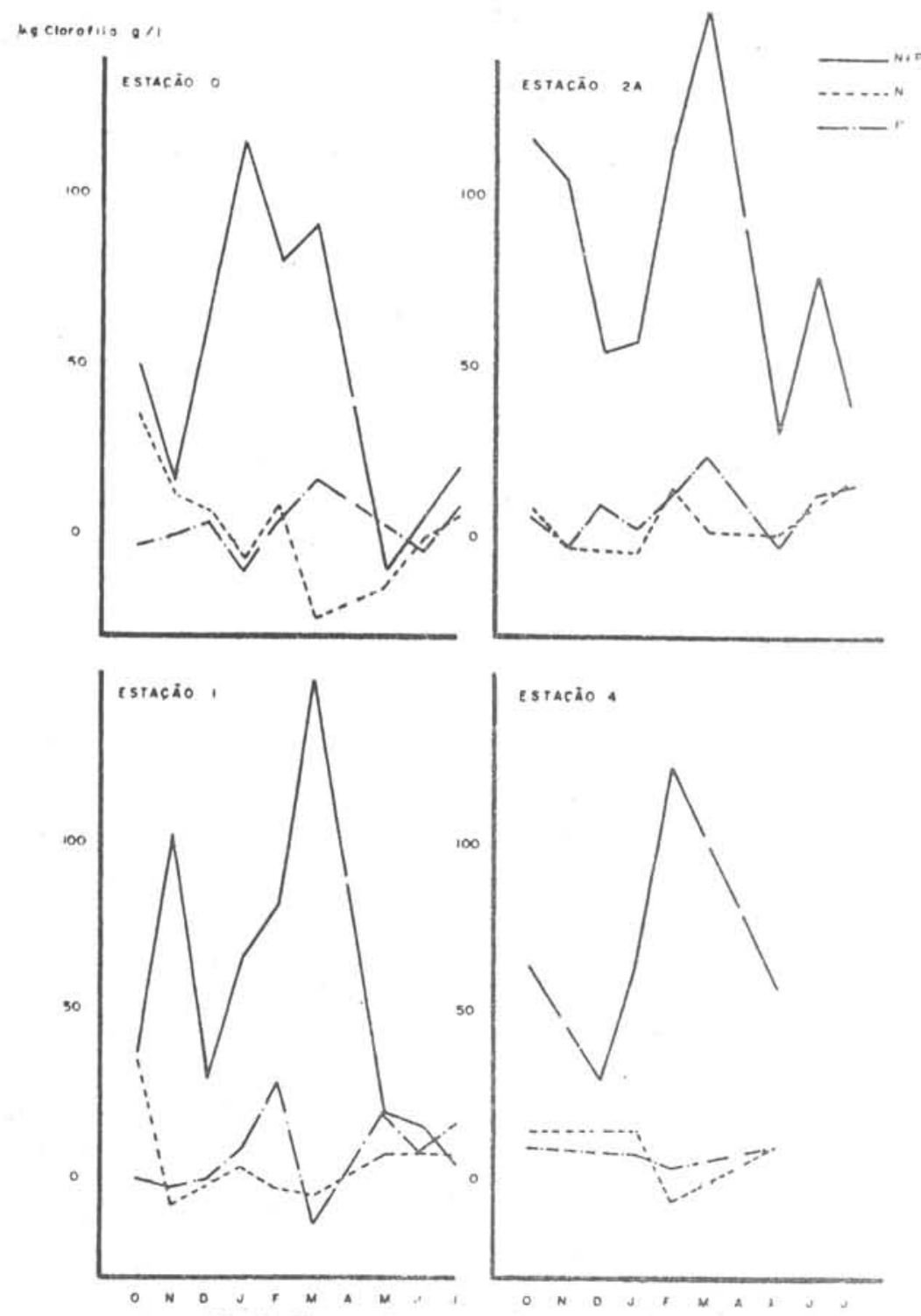

Fig. 5. Fatores limitantes, Outubro $77 / \mathrm{Julho} 78$. 
TABELA I - Variação Percentual dos Grupos de Fitoplâncton em Cada Estação no Período de Outubro/77 a Julho/78

\begin{tabular}{|c|c|c|c|c|c|c|c|c|c|c|c|}
\hline Estaçōes & Fitoplâncton & Out./77 & Nov./77 & Dez./77 & Jan./78 & Fev./78 & Mar./78 & Abr. $/ 78$ & Mai./78 & Jun./78 & Jul./78 \\
\hline \multirow{3}{*}{0} & Diatomáceas \% & 64 & 1 & 83 & 80 & 26,2 & 100 & - & 54,5 & 32,4 & 74 \\
\hline & Fitoflagelados \% & 32 & 44 & 14 & 20 & 62,3 & 0 & - & 45,5 & 32,4 & 18 \\
\hline & Outros \% & 4 & 55 & 3 & 0 & 11,5 & 0 & - & 0 & 35,2 & 8 \\
\hline \multirow{3}{*}{1} & DIATOMÁCEAS & 12 & 39 & 44 & 55 & 54 & 99 & - & 70,2 & 65,6 & 41,7 \\
\hline & FITOFLAGELADOS & 80,5 & 36 & 8 & 35 & 17 & 1 & - & 22,8 & 21,9 & 12,6 \\
\hline & OUTROS & 7,5 & 25 & 48 & 10 & 29 & 0 & $\overline{-}$ & 7 & 12,5 & 45,6 \\
\hline \multirow{3}{*}{$2 \mathrm{~A}$} & DIATOMÁCEAS & 5 & 85 & 60 & 22 & 84 & 91 & - & 43,3 & 39,5 & 61 \\
\hline & FITOFLAGELADOS & 95 & 4,5 & 18 & 72 & 14 & 18 & - & 50 & 53,5 & 11 \\
\hline & OUTROS & + & 10,5 & 2 & 6 & 2 & 1 & - & 6,7 & 7 & 28 \\
\hline \multirow{3}{*}{4} & DIATOMÁCEAS & 14 & - & 57 & 19 & 94 & - & - & 78,7 & 91,0 & 56 \\
\hline & FITOFLAGELADOS & 86 & - & 21 & 71 & 4 & - & - & 5 & 4,5 & 27,1 \\
\hline & \begin{tabular}{|l|} 
OUTROS \\
\end{tabular} & + & - & 22 & 10 & 2 & $\overline{-}$ & - & 16,3 & 4,5 & 16,9 \\
\hline
\end{tabular}

Entre espécies que se apresentavam dominantes em algumas das populações, destacamos: O gênero Nitzschia com Nitzschia pallea em destaque chegou por ela própria a ser dominante no mêe de março nas estações do Rio Jacuruna: uma $\mu$-Fragilaria, Phoeodactylum tricormutum, e algumas vezes $\mu$-fitoflagelados. Os dinoflagelados, incluídos neste grupo, têm na estação $2 \mathrm{~A}$ presença uma única vez salientada e tão só no mês de maio. Várias outras espécies, principalmente diatomáceas se apresentavam algumas vezes com certa frequêencia, imprimindo certa heterogeneidade em algumas populações. São os casos observados no mês de julho nas estaçōes $1,2 \mathrm{~A}$ e 4 , e no més de março na estação $2 \mathrm{~A}$.

\section{Discusato}

Segundo Margalef (1967) estuários são ecossistemas com populaçóes planctônicas pouco organizadas, devido à influência de frequentes variaçōes dinâmicas tanto químicas como físicas. Um estuário, acumula condições excepcionais num relativamente curto espaço físico para assegurar uma eficiente produção e decomposição orgánica. Estas condições são assim determinantes de acordo com Tundisi (1970) de ecossistemas viáveis a espécies euriplásticas pela sua resistência à pressão compensando o seu fraco potencial competitivo. Esta circunstância explicaria a dominância das pequenas diatomáceas Pennales relativamente a outros grupos, com os quais por vezes alternam. No caso dos fitoflagelados, também a presença dominante das formas nanoplanctônicas, sobretudo nas estaçōes 0 e 1 como ficou bem evidente nos dados da taxa fotossintética em que só a estação $2 \mathrm{~A}$ constituı uma exceçto. As concentrações celulares médias referidas para cada uma das estaç̃os, tem apenas interesse como valor relativo porquanto elas se basearam na densidade celular do controle (subcultura sem adição de nutrientes) dos testes biológicos de 120 horas.

A área estudada comportando uma média de $9 \times 10^{5}$ células por litro, parece deixar inferir que o fitoplancton não assume nela um papel de relevo.

A taxa fotossintética média variando de 9,52 a $10,93 \mathrm{mgC} /$ $/ \mathrm{m}^{3} / \mathrm{h}$ representou uma produtividade média de $\pm 45 \mathrm{~g} / \mathrm{C} / \mathrm{m}^{3} /$ ano ou $\pm 181 \mathrm{~g} / \mathrm{C} / \mathrm{m}^{2} /$ ano, nível que não coloca esta área como privilegiada comparativamente com outras no concernente a produção com origem no fitoplâncton. Tal como no estuário de $\mathrm{Ca}$ nanéia (Teixeira et al., 1967 e Tundisi, 1971), também aqui o nanoplâncton foi responsável pela absorção da maior parte do $\mathrm{C}^{14}$ (Fig. 4).

Assim, Hobson et al., citado por Fogg (1975), refere para a Corrente do Peru, uma média de $187,5 \mathrm{mgC} / \mathrm{m}^{3} / \mathrm{h}(=818 \mathrm{~g} / \mathrm{C} /$ $\left./ \mathrm{m}^{3} / \mathrm{ano}\right)$. Odum \& Odum (1955) apontam como taxa média para recife de coral no Pacífico Tropical cerca de $250 \mathrm{mgC} / \mathrm{m}^{3} / \mathrm{h}$, $\left(= \pm 1000 \mathrm{~g} / \mathrm{C} / \mathrm{m}^{3} / \mathrm{ano}\right)$.

No entanto Steemann Nielsen (1975) baseado também em dados de outros autores, situa a taxa fotossintética para o Golfo do México na ordem dos $2,3 \mathrm{mgC} / \mathrm{m}^{3} / \mathrm{h}$ (=10 gC/m 3 ano). A comparaçáo dos valores verificados na Baía de Todos os Santos com os observados por Teixeira et al., (1969) no estuário de Cananéia, reforça nossa anterior sugestão.

Reyssac (1975) citando dados da Baía de Lévrier (Mauritánia) que a qualifica de área fértil, refere valores médios à superfície de $40 \mathrm{mgC} / \mathrm{m}^{3} / \mathrm{h}$ no outono e $75 \mathrm{mgC} / \mathrm{m}^{3} / \mathrm{h}$ na primavera. O nível relativamente baixo encontrado para a produtividade primária do fitoplâncton na área SW da Baía de Todos os Santos admite-se ser devido à competição imposta pelos macrófitas do manguezal, visto que os fornecimentos de $\mathrm{N}$ e $\mathrm{P}$ se apresentam na área estudada em níveis médios, suficientes. As bruscas variaçōes nas concentrações destes elementos, por vezes observadas, seriam também conclusivas desta hipótese. Admite-se também que a pressão de água doce resultante da diferença de $350 \mathrm{~m} / \mathrm{h}$ entre as velocidades das correntes de fluxo e refluxo, (Peixinho et al., no prelo) explica aquelas bruscas variaçōes nos macronutrientes e também as taxas fotossintéticas relativamente baixas, significando que na área estuarina do rio Jacuruna, o efeito não coincide com a causa, achando-se aquele deslocado no sentido das maiores salinidades médias.

Nash citado por Perkins (1974), situa na Baía de Chesapeake concentraçōes a superfície numa faixa de $\Pi 1 / 23 \mu \mathrm{gN} / 1$ e no estuário do Rio Patuxent concentracões de $13 / 26 \mu \mathrm{gN} / 1$. Hall et al., (1977)-reportando-se a uma estação no estuário do rio Zambezi de reconhecida fertilidade, aponta concentracões médias de $58 \mu \mathrm{gP} / 1$ e de $68 \mu \mathrm{gN} / 1$ sendo a S\% $\%$ média daquela estação de 12,4 . Na relação $\mathrm{C} / \mathrm{N}$ (Fig. 2) da matéria orgánica particula$\mathrm{da}$, os picos mais evidentes em todas as estações nos meses de março e julho devem corresponder a uma maior quantidade de detritos no seston relativamente ao fitoplâncton, cuja relação $\mathrm{C} / \mathrm{N}$ é maior que a detrítica. Esta hipótese parece confirmada pela produtividade primária do fitoplâncton que decai em março e se torna insignificante no mês de julho, apesar de neste mês nem o N nem o P se apresentarem limitantes. A falta de dados na estação 4 no mês de março, mais dificulta uma razoável explicação para o discrepante resultado constatado na estação $2 \mathrm{~A}$ neste mesmo mês.

Baseando-se nossos resultados de PON na relação proteínas totais e nitrogênio da matéria viva, deve-se salientar que a relaçāo $\mathrm{C} / \mathrm{N}$ do seston, está obviamente super-estimada pelo fato de a fração detrítica ser a mais representativa na área estudada. Finenko \& Zaika (1973) verificaram haver uma relação clorofila a/seston em termos de carbono relacionada com a abundância do fitoplâncton a qual aumentava com o seu aumento. A mancha de relação $\mathrm{C} / \mathrm{N}$ (Fig. 6) assemelha-se muito a de estes autores no concernente aquela relação. A mancha na relação $\mathrm{C} / \mathrm{N}$ diz respeito a faixa de $400 / 1.400 \mathrm{mgC} / \mathrm{m}^{3}$, e de $4 / 28 \mathrm{mgN} / \mathrm{m}^{3}$, situando-se ao nível de fertilidade da Corrente das Canárias que segundo os mesmos autores se situam numa faixa entre 530 e $1.300 \mathrm{mgC} / \mathrm{m}^{3}$.

A diferença é que apesar de dizerem respeito a águas de alta produtividade, elas se referem a águas oceânicas. Por isso, somos levados a concluir não ter havido também, pelo menos 


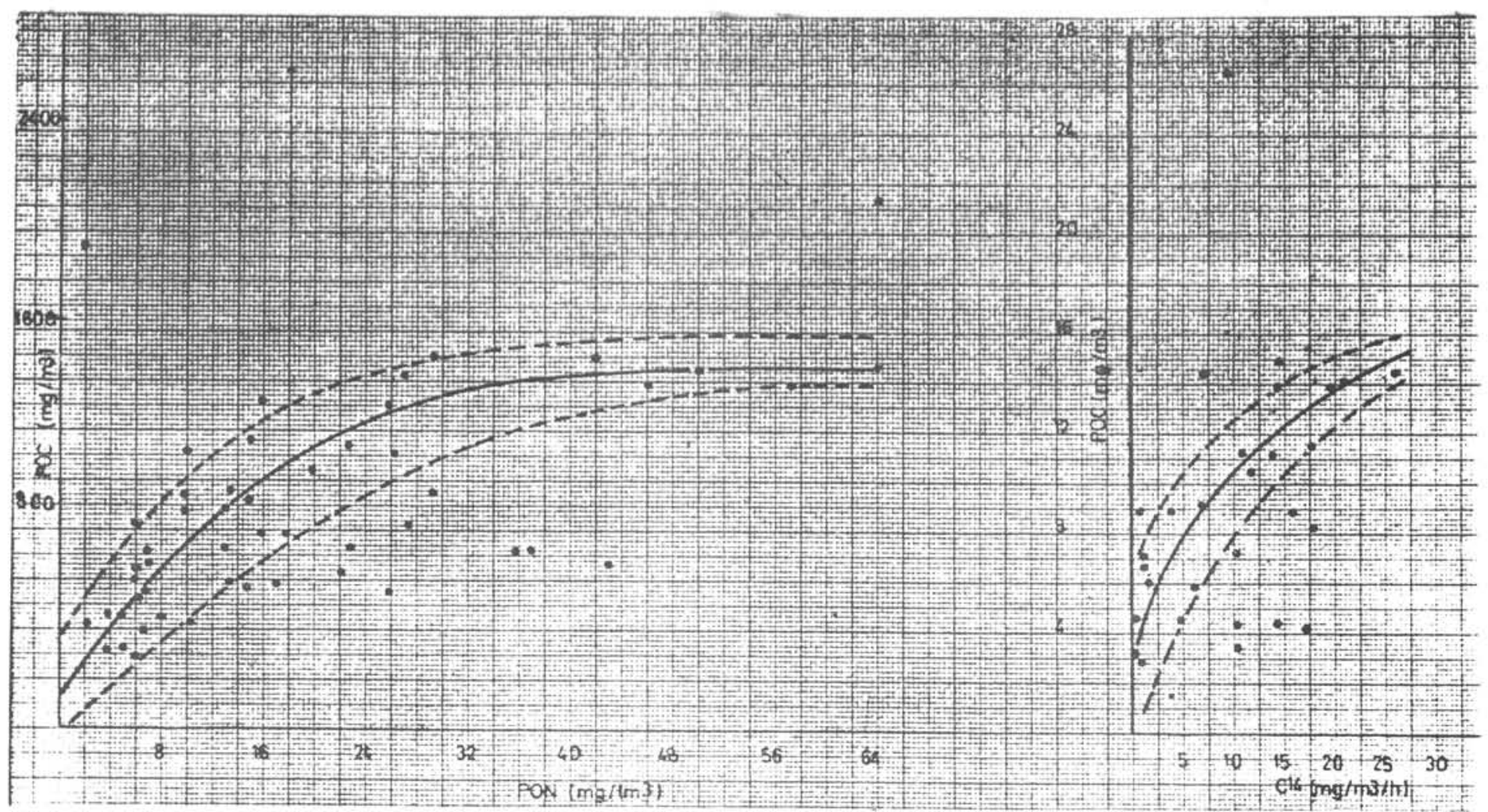

Fig. 6. Relaçāo carbono, nitrogênio particulado.

Fig 7. Relação carbonoparticulado e C14 absorvido pelo fitoplâncton.

no periodo de nossas investıgaçōes uma marcada alta contribuição dos detritos orgânicos na fertilidade da área SW da Baía de Todos os Santos, apesar da relevância destes relativamente ao fitoplâncton. Parsons (1975) reporta valores acima de $1 \mathrm{~g} \mathrm{C} / \mathrm{m}^{3}$ para a Baía de Chesapeake e Porto de Charleston.

A mancha de concentração na relação $\mathrm{POC} / \mathrm{C}^{14}$, prova haver também uma relação entre estes dois parâmetros (Fig. 7) embora menos evidente que a relação $\mathrm{C} / \mathrm{N}$. Finenko \& Zaika nao encontraram regularidade nesta relação. Todavia deve-se ter em conta que os dados do presente trabalho se acham restritos a uma área estuarina e os de estes autores dizem respeito a áreas oceânicas.

Pretende-se enfatizar que o DOC não avaliado neste estudo pode assumir por hidrólise num curto espaço de tempo $65 \%$ dos detritos de origem terrígena, segundo Bigs \& Flemer citados por Parsons (1975). Como é sabido, não só os detritos orgânicos podem entrar nas cadeias tróficas de invertebrados, mas também o carbono dissolvido. Neste caso, sugere Sórokin referido por Parsons (1975) que o DOC pode, além da sua utilização direta, desencadear, sobretudo em águas tropicais, o desenvolvimento rápido de agregados de bactérias que são utilizados no sustento dos invertebrados e mesmo do micro-zooplâncton. que em estuários devem assumir juntamente com fitoplâncton uma boa parte da energia carente para o desenvolvimento dos invertebrados filtradores.

Parece haver uma sucessão entre a taxa fotossintética e a relação $\mathrm{C} / \mathrm{N}$ particulada que explicaria os picos observados nesta relação nas amostras do mês de março: $\mathrm{O}$ hiato respeitante ao mês de abril impossibilita-nos de estender esta hipótese aos meses seguintes.

São dignas de nota as observações registradas no mês de março em que foram constatados os seguintes fatos:

1) Uma maciça invasão do estuário do Rio Jacuruna por plâncton constituído por medusas (Siphonophora) e copépodos.

2) Uma relevante presença de plâncton no Canal de Itaparica, com dominância de larvas zoea de Brachyurus e Sagița.

Apesar das limitaçōes enfrentadas na utilização de testes biológicos para identificaçāo e quantificação da carência ou não carência dos macro-elementos que estão na base da produção dos micrófitas e macrófitas num ecossistema do tipo sobre o qual incidirem nossas pesquisas, foi possível averiguar e tirar algumas ilaçōes.

Dentre estas, salienta-se a correlação inversa entre as taxas de fixação do carbono pelo fitoplâncton e muito provavelmente pelos macrófitas e aqueles macro-elementos como limj- tantes. Fevereiro e março sáo os meses que refletiram a situaçuo mais crítica, ao contrário dos meses de junho e julho que mostraram as situaçōes menos críticas entre todas, admitindo-se que os meses de agosto e setembro venham a revelar índices altos de produção primária. $\mathrm{O}$ nitrogênio parece ser o fator que na área estudada mais contribui para a limitação da produção primária.

\section{Agradecimentos}

Os autores desejam expressar seus agradecimentos aos Biólogos Welton Luis da Costa Rocha, Maria do Carmo Soares e Eliana Simas, pela sua valiosa colaboração no trabalho de campo e de laboratório e na confecção de gráficos.

\section{Bibliografia}

HALL, A. et al. 1977. The Zambezi River in Mocambique: the physico-chemical status of the Middle and Lower Zambezi prior to the closure of the Cabora Bassa Dam. Freshw. Biol., 7:187-206

FINENKO, Z. Z. \& ZAIKA, V. E. 1973. Particulate organic matter and its role in the productivity of the sea. In: Steele, J. H., ed. Marine food chains. Edinburgh, Oliver \& Boyd, v. 2. p. 32-44.

FOGG, G. E. 1975. Primary productivity. In: Riley, J P. \& Skirrow, G., eds. Chemical oceanography. 2 ed. London, Academic Press, v. 2, p. 385-453.

LORENZEN, C. J. 1967. Determination of chlorophyll and pheo-pigments: spectro-photometric equations. Limnol. Oceanogr., 12:343-346.

MARGALEF, R. 1967: The food web in the pelagic environment. Helgoländer wiss. Meeresunters., 15:548-559.

ODUM, E. P. 1971. Fundamentals of ecology. 3 ed. Philadelphia, Saunders, 574 p.

ODUM, H. T. \& ODUM, E. P. 1955. Trophic structure and productivity of a windward coral reef community on Eniwetok Atoll. Ecol. Monogr., 25:291-320.

PARSONS, T. R. 1975. Particulate organic carbon in the sea In: Riley, J. P. \& Skirrow, G., eds. Chemical oceanography. 2 ed. London, Academic Press, v. 2, p. 365-383.

PEIXINHO, V. M. C. 1972. Estudos preliminares sobre o fitoplâncton da Baía de Aratu. Dissertação de mestrado. Universidade de São Paulo, Instituto de Biociências.

PEIXINHO, V. M. C.; PAREDES, J. F. \& SIMAS, E. M. P. Standing 
TABELA II: ABUNDĀNCIA RELATIVA DO FITOPLĀNCTON

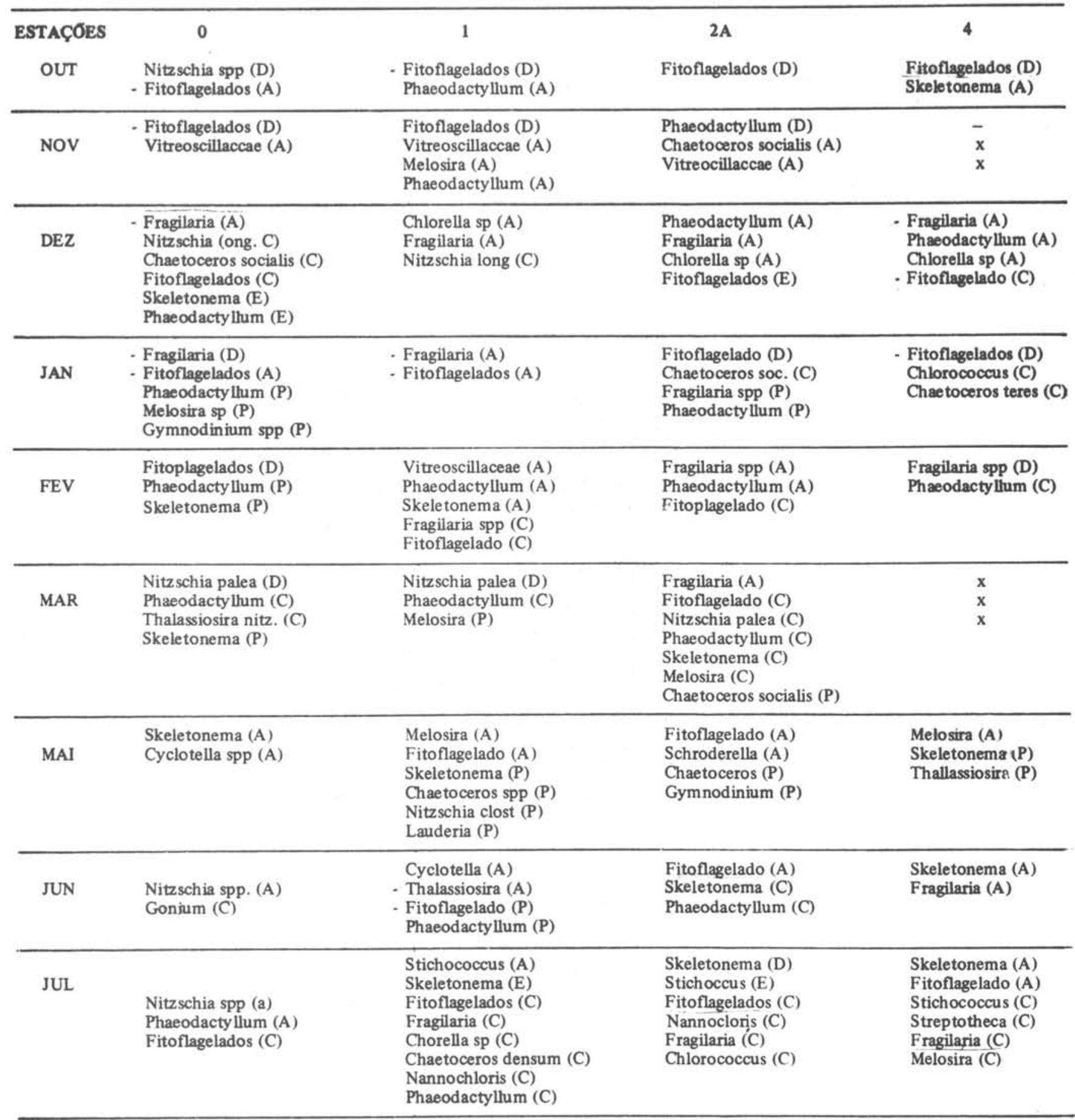

D, dominante $(\rightarrow 50 \%)$; A, abundante $(\rightarrow 25 \%)$;

C. comum $\quad(\rightarrow 10 \%)$; P, presente $(\rightarrow 2 \%)$.

crop na area estuarina SW da Baía de Todos os Santos. Boim Inst. oceanogr., S Paulo (no preio).

PERKINS, E. J. 1974. The biology of estuaries and coastal waters. London, Academic Press, 678 p.

PRICE, C. A. 1965. A membrane method for determination of total protein in dilute algal suspensions. Analyt. Biochem., $12: 213-218$.

REYSSAC, L. 1975. Evolution quantitative du phytoplancton de la Baie du Lévrier de septembre à novembre 1973. Bull. Mus. natn. Hist. nat., Paris, $3^{e}$ sér., (328), Ecol. genérale, 26:69-79.

SANTOS, J. J. 1973. Estudo preliminar, principalmente do plâncton, das águas da Baía de Todos os Santos. Bolm Zool Biol. mar., n.s., S Paulo, 30:419-447.

STEEMANN-NIELSEN, E. 1975. Marine photosyntesis with special emphasis on the ecological aspects. Elsevier Oceanogr. Ser. Amsterdam, Elsevier, 14 ip.

STRICKLAND, J. D. H. \& PARSONS, T. R. 1972. A practical handbook of seawater analysis. 2 ed. Bull. Fish. Res. Bd Can. 167:1-311.
TEIXEIRA, C 1973. Prelimmary studies of primary production in the Ubatuba region (Lat. 23ㅇ 30'S - Long. 45 06 'W). Brazil. Bolm Inst. oceanogr., S Paulo, 22:49-58.

TEIXEIRA, C. \& TUNDISl, J. 1967. Primary production and phytoplankton in Equatorial waters. Bull. mar. Sci. 17(4) 884-891.

TEIXEIRA, C.; TUNDISI, J. \& SANTORO-Y. J. 1969. Plankton studies in a mangrove environment VI. Primary production, zooplankton standing-stock and some environmental factors. Int. Revue ges. Hydrobiologie, S4(2):289-297.

TUNDISi, J. 1970. O plancton estuarıno. Contrções Inst. oceanogr Univ. S Paulo, sér. Ocean. biol. 19:1-22.

TUNDISI, J. G. 1971. Size distribution of the phytoplankton and its ecological significance in tropical waters. In: Costlow Jr., J. D., ed. Fertility of the sea. New York, Gordon \& Breach, vol. 2, D, 603-612.

ZIMMERMANN, C. 1916. Flora diatomológica do plankton superficial da bahia da cidade do Salvador. An. $5^{\circ}$. Congr. bras. Geogr., 1:448-461. 